\title{
IRMANDADES NEGRAS, RECONHECIMENTO E CIDADANIA
}

\author{
Ema Pires (Universidade de Évora, IHC-CEHFCi-UÉ e PPGAS/UnB) \\ Vinicius Santos da Silva (UFMG)
}

SILVA, Renata Nogueira da. Irmandades Negras, Reconhecimento e Cidadania. Curitiba:Appris, 2016.

O livro "Irmandades Negras, Reconhecimento e Cidadania", publicado pela Editora Appris em 2016, é o resultado de pesquisas realizadas por Renata Nogueira durante seu percurso acadêmico, sua monografia de graduação e duas dissertações de mestrado realizadas. Renata Nogueira da Silva é doutoranda e mestre em Antropologia Social pela UnB - Universidade de Brasilia, mestre em Sociologia pela (UFG- Universidade Federal de Goiás), graduada em ciências sociais pela UFU (Universidade Federal de Uberlândia) e professora de Sociologia da Secretaria de Educação do Distrito Federal (SE/DF).

O prefácio do livro é da autoria da professora Kelly C. da Silva, professora associada do Departamento de Antropologia da UnB. Com uma promissora produção científica e atuação sócio-política no estudo das práticas congadeiras, Renata Nogueira aprofunda em Irmandades Negras, Reconhecimento e Cidadania as pesquisas anteriormente realizadas, agora revisitadas em um estudo que articula as complexas relações que se tecem entre processos de patrimonialização, políticas sociais e culturais brasileiras.

$\mathrm{Na}$ introdução do seu livro, Renata Nogueira da Silva faz uma incursão que possibilita o leitor envolver-se e compreender o contexto de surgimento e criação das irmandades negras no Brasil, pontuando os motivos, conceitos e olhares acerca das comunidades congadeiras. Além disso, introduz sua reflexão acerca do caminho de valorização e legitimação das políticas culturais brasileiras que tocam a congada, refletindo sempre acerca do seu papel como antropóloga neste estudo.

O livro é composto por três capítulos: I) Irmandades negras: zonas de negociação nos encontros coloniais; 2) Práticas congadeiras, Irmandade de São Benedito e projetos culturais; 3) Políticas culturais: intersecções entre local, nacional e internacional.

No primeiro capítulo, a autora dedica seus apontamentos às Irmandades de São Benedito e Nossa Senhora do Rosário, fazendo uma revisão bibliográfica que possibilita um entendimento sumário das Irmandades Negras. Em seguida, estabelece uma análise pormenorizada dos processos pelos quais a Irmandade de Ituiutaba estabeleceu-se como entidade político religiosa e de mediação das demandas negras, desde sua constituição até às demandas contemporâneas. Perpassa de forma sincera todas as disputas e negociações necessárias para a constituição, como a fé católica, que serviu como índole humanitária para o projeto colonial português. A autora exemplifica negociações realizadas entre os atores deste período, como o surgimento das Irmandades Negras, que serviam para acalmar as disputas existentes no contexto, além desta tornar-se 
uma possibilidade de organização civil, sendo às vezes a única forma de garantir pequenos direitos para a população africana escravizada.

Nogueira da Silva ressalta que a população africana em sua multiplicidade percebeu que a ressignificação da fé católica imposta pelo império poderia ser uma forma de reativar sua memória, reunião social e suas tradições. Segundo a autora, a prática de eleger e coroar reis do Congo foi uma forma criativa de transpor os processos sociais na diáspora africana, pontuando também que este mesmo processo foi usado pela dinâmica colonial para subverter esse importante processo social africano em figuras rituais, transformando o poder político de outrora em um poder simbólico e de manejo do sagrado.Além disso, a autora pontua a importância dos mitos fundadores das congadas, que contam com a escolha e proteção por parte de Nossa Senhora aos escravos.

Após a explanação do início das Irmandades Negras, A autora retoma uma das suas pesquisas sobre as práticas congadeiras em ltuiutaba/MG. Para isso, relembra eventos e situações que convergiram para a criação das irmandades nesta região. Inicia uma análise mais detalhada da criação da Irmandade de São Benedito, que se dá através de um acompanhamento próximo do grupo e relatos coletados nesta pesquisa. Faz uma análise fundamentada e articulada de que a criação da irmandade acompanha a expansão da valorização e reconhecimento das práticas afro-brasileiras após o Estado Novo brasileiro, que buscou um projeto nacionalista. Ao descrever a história constitucional da irmandade, a autora relembra que os processos são interpretados de forma diferente pelos integrantes, não escondendo as negociações internas dentro da própria instituição. Segundo a autora são formas de religiosidades misturadas e sobrepostas, que se articulam para sua própria sobrevivência. São descritas as lutas para legitimação da prática congadeira, como os embates com a igreja e a inserção das práticas congadeiras no calendário do catolicismo oficial.Além disso, retrata também a transposição de experiências traumáticas vividas no período escravocrata para a própria prática congadeira, como a hierarquia aos capitães, ou o respeito às madrinhas das bandeiras e principalmente o motivo de ancestralidade dentro da organização interna. Mesmo assim, a autora não esconde que há uma disputa geracional, onde atualmente os mais jovens estão retomando a defesa dos modos antigos do fazer congadeiro.

Já no segundo capítulo, a autora aproxima o foco da Irmandade de São Benedito de Ituiutaba, fazendo uma análise diacrónica de sua história e sua continuidade na contemporaneidade. Para isso, demonstra como o processo de constituição se constrói como uma possibilidade de garantia de direitos historicamente negados às comunidades e culturas afro-brasileiras da região. A irmandade surge como meio de positivação e ressignificação de narrativas do tempo de escravidão, através da música, danças e releitura do passado. A atualização do passado nos tempos atuais, juntamente com a fé em Nossa Senhora do Rosário e São Benedito, faz com que a criação de um sentimento igualitário surja entre a comunidade, proporcionando novas visões sobre si e sobre o outro.

Renata Nogueira da Silva insere no texto um emocionante relato da filha de Dona Geralda, uma figura emblemática na constituição do terno Camisa Rosa. As memórias coletivas são perpassadas pela memória individual de Maria Lúcia, que conta de forma detalhada a história de sua mãe no processo de constituição do Camisa Rosa. 
De forma pertinente, a autora articula as ações contemporâneas, realizadas através de projetos como Petizada na Congada e Congo Filhos da Luz, com o processo de legitimação, reconhecimento e pertencimento das práticas congadeiras na cidade de Ituiutaba. Esses projetos acabam por tornarem-se importantes ações afirmativas da prática congadeira, além de envolver a comunidade de forma a atualizar as novas gerações.

A autora sublinha a importância da execução de projetos como o Congo Filhos da Luz em um CAIC (Centro de Atenção Integral à Criança), os quais, com o esforço de agentes públicos e comunitários, conseguem valorizar o conhecimento tradicional afro-brasileiro, muitas vezes subvalorizado nas escolas brasileiras. Além de envolver os jovens com atividades da congada, também positiva o imaginário coletivo e tenta acabar com velhos preconceitos enraizados na sociedade.

Fazendo um paralelo ao exemplo supra mencionado, a autora remonta brevemente o histórico de ações afirmativas implantadas no Brasil em consonância com o movimento de políticas globais acerca do assunto, demonstrando as ações locais contextualizadas em um âmbito global. Assim, Renata Nogueira da Silva reflete sobre as possibilidades de uma prática cultural como o congado que extrapolam suas próprias intenções e acabam por atingir um objetivo muito maior, como a inclusão etnicorracial. Já o projeto Petizada na Congada é exemplificado como uma ação extremamente eficaz na positivação da identidade negra local, como demostra um relato da avó ao analisar a atitude de sua neta, participante do projeto, perante a sociedade. Estes projetos, além de dinamizar a vida social da comunidade, também mobilizam o entorno e as novas gerações no envolvimento com a festa, além de integrarem uma agenda de políticas públicas.

Ampliando a visão antropológica, no terceiro capítulo a autora faz uma articulação entre os processos políticos globais e locais e o reconhecimento das práticas congadeiras no Brasil. Para isso, Renata Nogueira da Silva aponta que os processos globais de reconhecimento e proteção das culturas negras, além do processo histórico de ampliação do conceito de cultura, estão intimamente atrelados aos progressos percebidos nas políticas nacionais e municipais, em Ituiutaba. Com isso, as Irmandades Negras têm resgatado na contemporaneidade as suas atribuições solidárias e de busca de direitos como no período colonial, produto de mediações possibilitadas pela relação em desenvolvimento entre a irmandade e o setor público.

A autora faz um apanhado das transformações do conceito de cultura nos sessenta anos da UNESCO, os desdobramentos nas políticas públicas no Brasil e em Ituiutaba na valorização do patrimônio afro-brasileiro, sem obliterar de contextualizar os esquecimentos produzidos durante os projetos de construção de uma identidade nacional. A autora, sob a luz de autores que analisaram o desenvolvimento do conceito de cultura, ressalta que essa se torna uma importante ferramenta para fortalecer identidades étnicas, reconhecer conquista de direitos e tonificar a diversidade cultural. As orientações da UNESCO guiam e possibilitam a elaboração de políticas públicas locais com contornos específicos, como é o caso de Ituiutaba. Silva relembra que este processo de construção e desenvolvimento das políticas públicas no Brasil não foi homogênea e sem conflitos, e que, o que foi considerado patrimônio no Brasil desconsiderava amplamente 
o que não era patrimônio construído. A autora aponta o desenrolar da política pública de cultura do Brasil, apontando marcos importantes no reconhecimento do patrimônio imaterial e grupos anteriormente silenciados. Este processo de reconhecimento do patrimônio imaterial vem como uma necessidade do Brasil de inserir-se na agenda de discussão internacional, principalmente na visão de cultura como potente ferramenta de desenvolvimento local. Neste ponto, Silva faz um compêndio completo da criação de leis e organismos que buscam o reconhecimento e fortalecimento da população negra através da cultura, como a Fundação Palmares, vinculada ao Ministério da Cultura.

Segundo a autora, o desenvolvimento de políticas públicas nacionais de reconhecimento e proteção da cultura afro-brasileira possibilitou que agentes do âmbito municipal pudessem apropriar-se e adaptar às realidades locais. Este processo local se deu principalmente pelo envolvimento de atores ligados às comunidades e movimentos negros de ltuiutaba, sendo a irmandade importante agente deste processo. $O$ envolvimento da irmandade é visto como uma possibilidade de acessar direitos historicamente negados às comunidades negras, como a participação em editais e acesso à recursos públicos para realização de projetos que salvaguardem suas práticas culturais. $O$ acesso à esses editais significa alcance à territórios de poder antes inalcançáveis, possibilitando a execução de projetos de cidadania, gerando um empoderamento social e político que viabiliza acesso à direitos anteriormente negados. Nogueira da Silva demonstra diversos exemplos de ações promovidas ou que a irmandade é convidada a participar que gera um fluxo constante de reconhecimento e positivação das práticas congadeiras.

Em suma, o livro de Renata Nogueira da Silva articula, de um modo particularmente habilitado, teoria e empiria, numa detalhada e densa etnografia que permite à/ao leitor(a) uma compreensão das Irmandades Negras, não deixando de demonstrar sempre as negociações e contradições necessárias para sua manutenção. $O$ contexto de Ituiutaba possibilita questionamentos que podem levar a novos estudos. A articulação entre políticas públicas globais, nacionais e municipais, juntamente com o relato das irmandades negras possibilita uma visão integral das práticas congadeiras. Um livro completo para servir de base para estudos de outros campos antropológicos, pois extrapola o relato de campo e possibilita uma análise completa do objeto de estudo.

No xadrez global de conexões e espaços intersticiais que articulam agencias e subjectividades (de)coloniais, esta publicação introduz dimensões de análise claramente inovadoras para uma compreensão mais ampla do Brasil contemporâneo, dos usos sociais dos patrimónios, dos processos de reciclagem do passado e da condição colonial. 